\title{
Bench Testing and Modeling Analysis of Optimum Shifting Point of HMCVT
}

\author{
Yu Qian $(\mathbb{D})^{1}$ Zhun Cheng $(\mathbb{D})^{2}$ and Zhixiong Lu ${ }^{1}{ }^{1}$ \\ ${ }^{1}$ College of Engineering, Nanjing Agricultural University, Nanjing 210031, China \\ ${ }^{2}$ College of Automobile and Traffic Engineering, Nanjing Forestry University, Nanjing 210037, China \\ Correspondence should be addressed to Zhixiong Lu; 1248687161@qq.com
}

Received 5 January 2021; Revised 20 April 2021; Accepted 24 April 2021; Published 5 May 2021

Academic Editor: Atila Bueno

Copyright ( 2021 Yu Qian et al. This is an open access article distributed under the Creative Commons Attribution License, which permits unrestricted use, distribution, and reproduction in any medium, provided the original work is properly cited.

\begin{abstract}
The unreasonable shift point will cause a large shift impact, which will affect the engine fuel economy and the service life of the wet clutch. To decrease shift impact on agricultural tractors with HMCVT (Hydromechanical Continuously Variable Transmission) and find the best working point, the following methods are proposed in this paper: firstly, conducting all-factor method and response surface method (RSM) to design and carry out bench test of shift impact; secondly, using the basic linear fitting, RSM, and stepwise regression analysis to establish comprehensive mathematical models and selecting models with high prediction accuracy; thirdly, putting forward the method of determining the weight of variance to match parameters of three quality evaluation indexes with inconsistent correlation; finally, establishing the total shift quality evaluation index and obtaining the optimal shift working point. It is found that oil filling pressure has a significant effect on speed drop, while the engine speed has a significance on the dynamic load and sliding friction. To make the transmission section of the best quality, the oil pressure at this time is $1 \mathrm{MPa}$ and the engine speed is $1040 \mathrm{r} / \mathrm{min}$. The results show that the proposed method can determine the optimal shift point and provide a reference for developing the control strategy.
\end{abstract}

\section{Introduction}

Hydromechanical Continuously Variable Transmission (HMCVT) consists of a hydraulic system (pump-motor) and mechanical system (gears). HMCVT can achieve a wide range of speed and the power will not be interrupted while shifting [1-4]. Tractors working in the field need to change stages frequently to meet different workloads. At the same time, it will be a great shift impact for tractors that change sections frequently. Shift impact will decrease the fuel economy of tractors and accelerate abrasion of friction plates in wet clutch, so as to reduce the driving comfort [5-7]. In recent years, there is a certain degree of research on shift quality.

At present, HMCVT shift quality is mainly studied from two aspects: shift control and factors affecting shift quality. Literature $[8,9]$ discussed the influence of volumetric efficiency of the hydraulic system on shift quality from the perspective of segment change control and proposed to control HMCVT by using the electronic controller of the fuzzy control algorithm to reduce shift impact.
For the study of factors affecting the shift quality, Manish et al. [10] built the vehicle dynamics model and control logic to study the influence of clutch pressure on output torque. Zhang et al. [11, 12] analyzed the influence of clutch oil pressure and resistance on the shift quality by simulation model; however, the reliability of the rule was low because of less test times. $\mathrm{Ni}$ et al. [13] selected five factors, such as clutch shift time, oil pressure, and speed regulating valve flow, and conducted an orthogonal test on the test bench to study the influence of relevant factors on the shift quality. However, due to the single analysis method of test data, it was impossible to determine the reasonable value of clutch shift time which has a contradictory relationship with the speed drop and shift impact. Peng et al. [14-16] carried out multifactor combined clutch loading tests and timing optimization tests to study shift quality. However, the contradictory relationship between different evaluation indexes was not considered.

By summarizing the current research status of shift quality, it is found that the traditional shift test analysis uses 
range and method analysis to obtain the ranking of the influence significance of the selected factors and selects a group of working points which make the quality optimal from the factor level of the test. The value of this method is a discrete point, and the true optimal solution within the whole value range cannot be found.

Therefore, this paper proposes to establish a mathematical model between the evaluation index of shift quality and the influencing factors. The value range of this modeling method is continuous and not limited to the specified working conditions, so that the optimal shift point within the value range can be found and the shift quality can be predicted under different working conditions.

Specifically, this paper adopts two classical linear modeling methods; response surface method (RSM) and stepwise regression analysis are used to establish mathematic models of speed drop, dynamic load, and sliding friction about engine speed and oil pressure of wet clutch.

The model with the highest precision is selected to establish the comprehensive evaluation index of shift quality. On the one hand, this paper aims to reduce the number of tests and improve the utilization rate of test results. On the other hand, it provides a theoretical basis for determining the optimal switching point and switching control strategy of HMCVT.

The rest of the paper is organized as follows. Section 2 contains the transmission principle of HMCVT and shift test bench. Section 3 contains two methods for the experimental design of shift and result analysis. Section 4 contains the comparison of prediction accuracy between two modeling methods. Section 5 contains the solutions of optimal shift point. Section 6 contains the conclusions. The specific technical flowchart is shown in Figure 1.

\section{HMCVT Test Bench and Two Methods for the Experimental Design of Shift}

2.1. Introduction to the Principle of HMCVT. HMCVT is composed of two parts in parallel, one part is the hydraulic system and the other is the mechanical system. The hydraulic system includes pump-motor and oil passage for lubrication and coolant. The mechanical system includes gearbox and planetary. The power transmission route of HMCVT is as follows: starting from the engine, the power is divided into two parts when entering the HMCVT. One part goes into the planetary row through the hydraulic system, and the other part goes into the planetary row through the mechanical system. The power of two parts merged into one under the action of the planetary row, and the power goes into the power-output shaft finally. The transmission ratio of the mechanical system is determined by the gears and it cannot be changed, while the transmission ratio of hydraulic transmission can be changed by changing the displacement of the variable pump. The output speed of HMCVT can achieve continuous change in the segment. At the same time, the transmission ratio of synchronous switching is determined to realize continuously speed regulation [17-19].

HMCVT designed by our research group is shown in Figure 2. The transmission has three power transmission routes. The first route $\left(\mathrm{HM}_{0}\right)$ is controlled by variable pump, constant motor, and wet clutch $C_{0}$. The second route $\left(\mathrm{HM}_{1}\right)$ is controlled by gear pairs, planetary row $P_{1}$, and wet clutch $C_{1}$. The third route $\left(\mathrm{HM}_{2}\right)$ is controlled by gear pairs, planetary row $P_{2}$, and wet clutch $C_{2}$. $\mathrm{HM}_{2}$ section is taken as an example to describe transmission route of power briefly.

When working in $\mathrm{HM}_{2}$ section, some of the engine power goes through $i_{1}-i_{2}$ gear pairs and hydraulic system and finally reaches sun gear of planetary row $P_{1}$. The other part power goes through $i_{3}-i_{5}$ gear pairs and finally reaches planet carrier of planetary row $P_{1}$. Through the confluence of planetary row $P_{1}$, the power is delivered to the output shaft through gear ring of planetary row $P_{1}$. This paper studies $\mathrm{HM}_{1}$ segment for $\mathrm{HM}_{2}$.

2.2. Test Bench of HMCVT. Our research group built a test bench according to HMCVT transmission principle in Figure 3 . The test bench mainly consists of driving system, controlling and test system, transmission system, and simulate loading system.

The driving system includes the Deutz TCD2013L062V diesel engine. The power rating of the engine is $197.7 \mathrm{kw}$ and the rated speed is $2300 \mathrm{r} / \mathrm{min}$. The simulated system mainly consists of DW250 eddy current dynamometer. The maximum power of the dynamometer is $250 \mathrm{kw}$ and the rated speed is $2000 \mathrm{r} / \mathrm{min}$. The test control system consists of Industrial Personal Computer, slave computer, torque-speed sensors, and data acquisition module. The model of Industrial Personal Computer is ICP-610H. The slave computer is based on Labview programming software to develop measurement and control system. Torque-speed sensors come from Jiangsu Lanmec Electromechanical Equipment Company. The model of data acquisition module is ADAM4117.

When the host computer issues control instructions, firstly, the data acquisition module collects the control signal. Then the signals are processed by low-pass filtering. In the end, the processed signals will be collected by the salve computer and recorded to a table file for subsequent data processing.

2.3. Evaluation Index of Shift Quality. HMCVT depends on the opening and closing of wet cutch to realize segment change. The shift quality refers to the ability to realize shift smoothly on the premise of ensuring the power of the tractor. This paper evaluates the shift quality of HMCVT from three aspects: the fluctuation of rotating speed and torque and the friction heat generated by wet clutch during changing section. Speed drop, dynamic load, and sliding friction are selected as evaluation indexes in this paper [20-22].

(1) Speed drop

Speed drop refers to the fluctuation range of output speed of the transmission when host computer gives the instruction to change the segment.

$$
\eta_{1}=\left|\omega_{\min }-\omega_{0}\right| .
$$




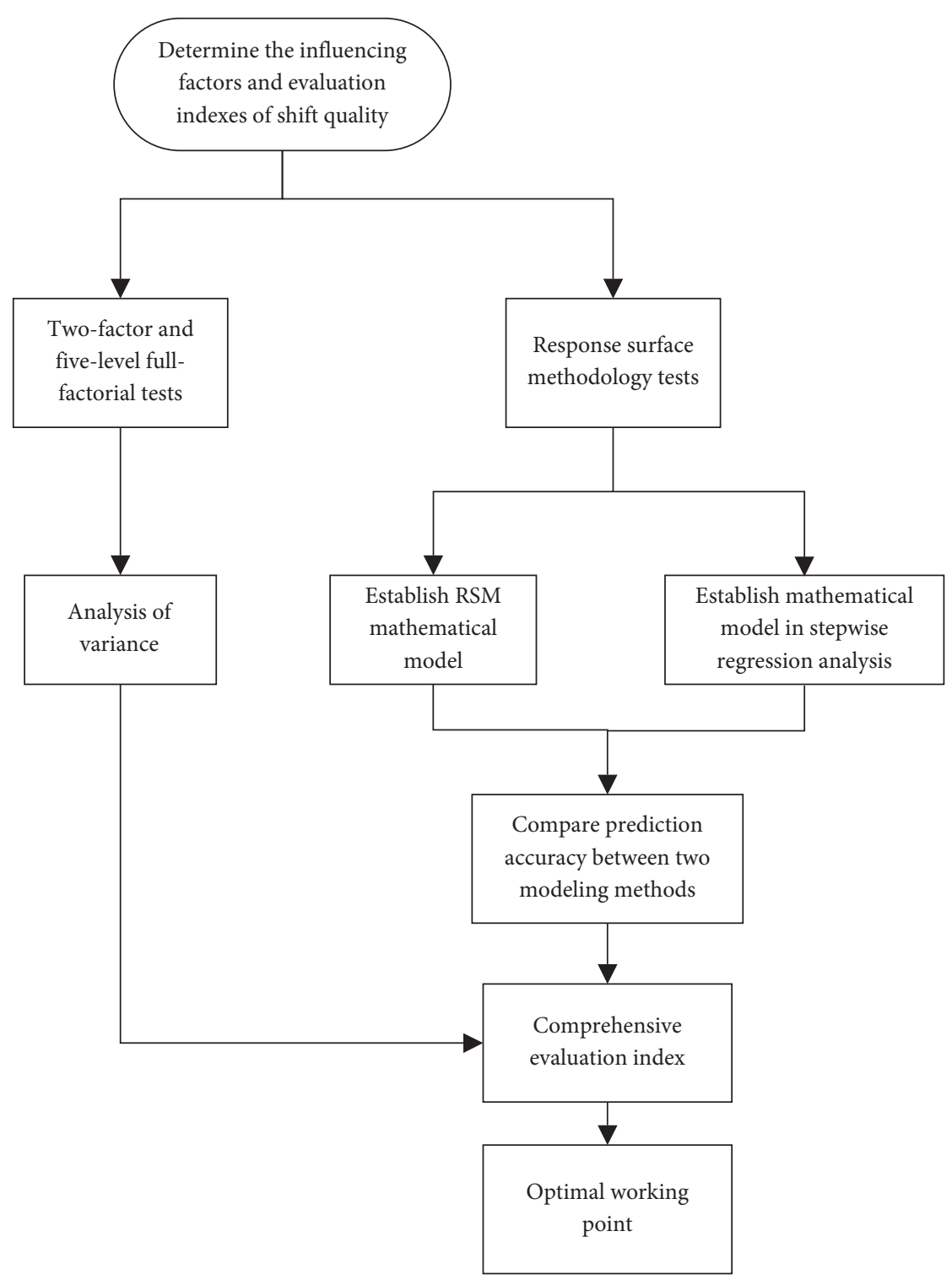

FIgURE 1: Technical flowchart.

In the above formula, $\omega_{\min }$ refers to the minimum speed of output shaft during the shifting process; $\omega_{0}$ refers to the stable speed of output shaft during the shifting process.

(2) Dynamic load

Dynamic load refers to the ratio of the maximum torque of output shaft to the stable torque of output shaft during the shifting process.

$$
\eta_{2}=\left|\frac{T_{\max }}{T_{0}}\right| .
$$

In the above formula, $T_{\max }$ refers to the maximum torque of output shaft during the shifting process, and $T_{0}$ refers to the stable torque of output shaft during the shifting process.

(3) Sliding friction
During the shifting process, the clutch goes through a sliding and friction stage. Firstly, in the working clutch, the rotational speed of driving plates is different from that of the following plates. When the driving plates and the following plates are compressed by oil pressure, the driving plates and the following plates reach the same rotational speed eventually.

In this stage, the work produced by the working clutch is sliding friction work, which will be converted into heat. The friction pieces will overheat easily when shifting frequently. Sliding friction work will cause friction pieces to warp, crack, or even fail.

The sliding friction work is mainly related to the rotational speed difference of the driving plates and following plates, the duration of sliding friction, and the pressure on the friction plates.

$$
\eta_{3}=\int_{t_{1}}^{t_{2}} T\left(\omega_{\mathrm{d}}-\omega_{f}\right) d t .
$$



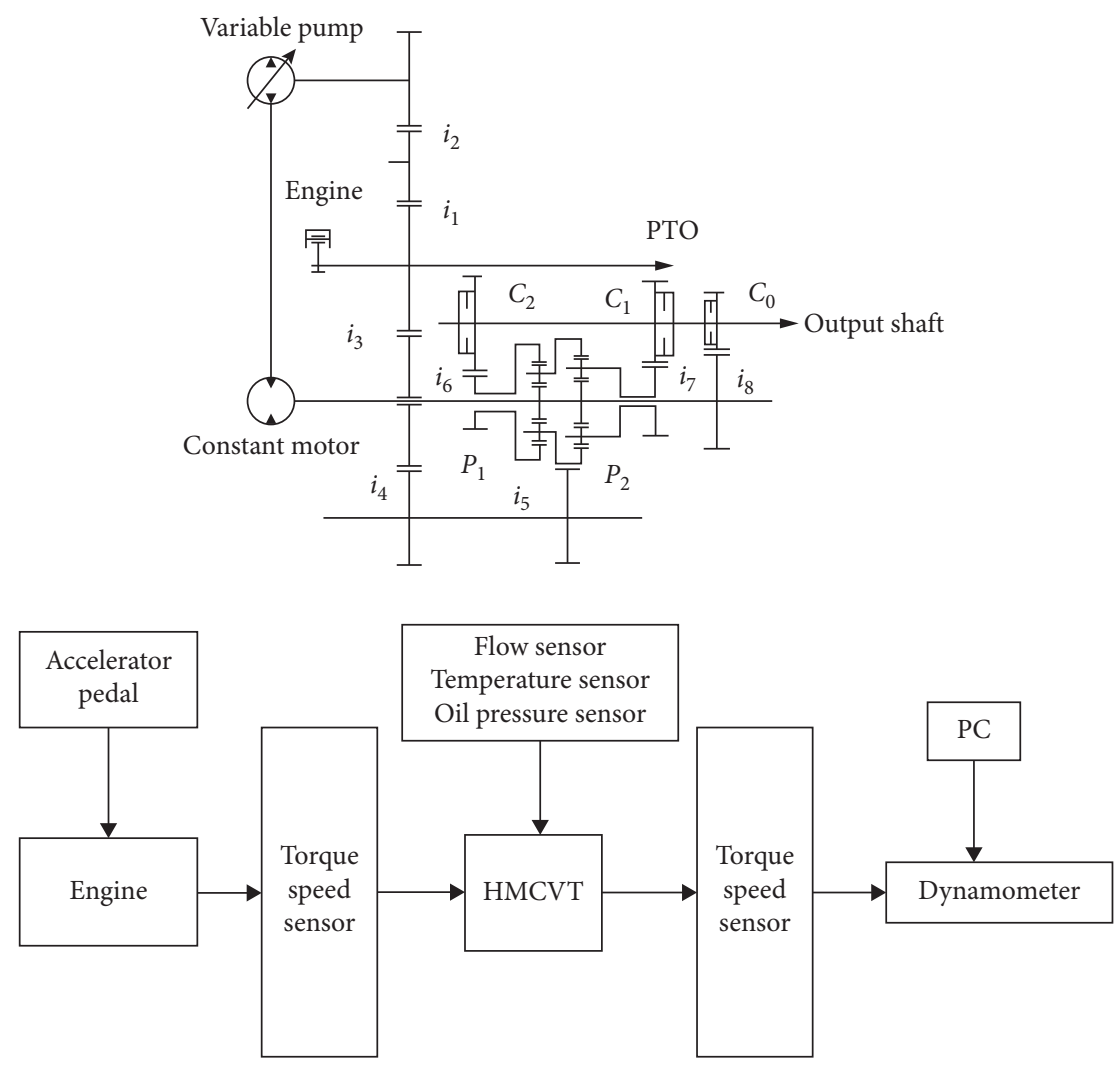

FIgURE 2: Schematic diagram of HMCVT.

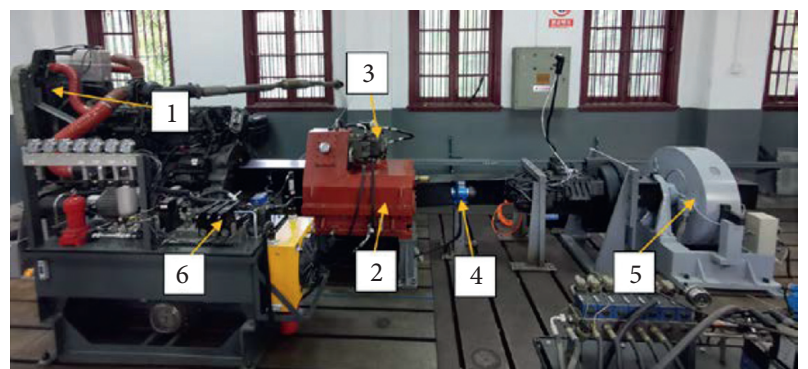

Figure 3: Test bench of HMCVT. (1) Engine. (2) HMCVT. (3) Pumpmotor system. (4) Rotating speed-torque sensor. (5) Speed-up box. (6) Electric eddy current dynamometer. (7) Hydraulic control system and lubrication system of wet clutch.

In the above formula, $T$ refers to friction torque of wet clutch, $\omega_{\mathrm{d}}$ refers to the rotational speed of driving plates, $\omega_{\mathrm{f}}$ refers to the rotational speed of following plates, $t_{1}$ refers to the start time of sliding, and $t_{2}$ refers to the end time of sliding. The research flowchart of comprehensive shift quality evaluation index is shown in Figure 4.

\subsection{Full-Factorial Experimental Design of Shift.} Full-factorial design means that all factors at all levels are tested at least once in the design. This method can accurately estimate the size of the main effect of each experimental factor and the size of the interaction effect of each level of factors. And the operation of this method is simple and the result is accurate.
According to the preliminary test results, this paper selects the oil pressure of the hydraulic system and engine speed as two variables of the shift bench test and evenly selects five levels of each variable within the value range. The reasonable value range of two variables is obtained from the preliminary test. The reasonable value range of oil pressure is $1-5 \mathrm{MPa}$; the reasonable value range of engine speed is 1040-1440 r/min. The two-factor and five-level full-factorial tests were conducted for a total of 25 times. The design table is shown in Table 1.

2.5. Response Surface Methodology Experimental Design of Shift. Response surface methodology is an experimental design method $[23,24]$, which is a synthesis of experimental design and mathematical modeling. The functional relationship between factors and results is fitted through the limited experimental design of representative local points. There are a variety of response surface test design methods. This paper adopted Central Composition Design (CCD) since the level of the shift test is 5. The CCD method is also called star design, and its design table includes axial point and center point. The CCD method takes 5 levels for each factor. The five levels are coded as $(0, \pm 1, \pm \alpha)$ and 0 is the center point.

According to the determined value of oil pressure and engine speed, the CCD combination design method in the auxiliary software Design-Export was adopted to determine the experimental scheme of the influence law of two variables on the shift quality. The design table is shown in Table 2. 


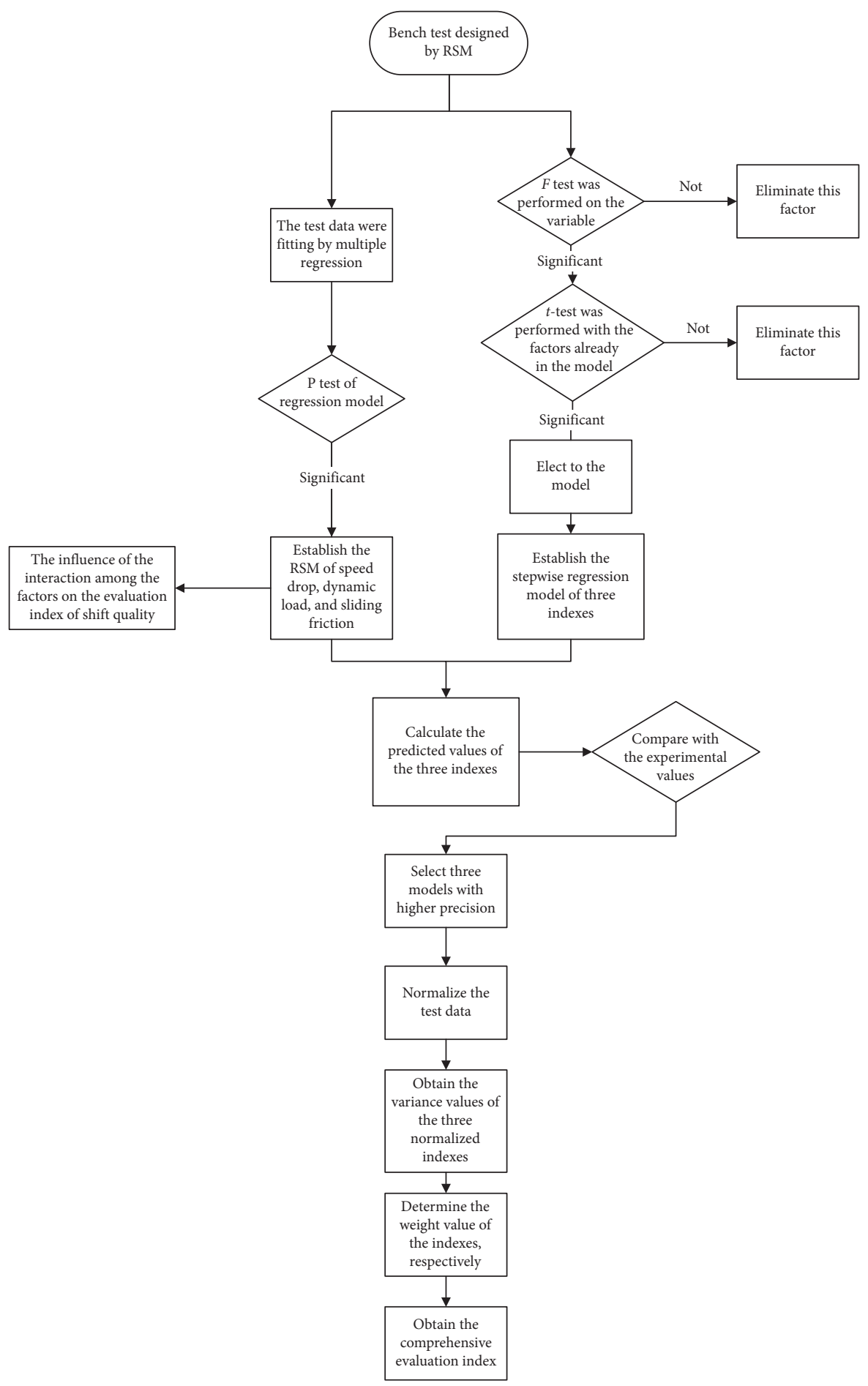

FIGURE 4: Research flowchart of comprehensive shift quality evaluation index.

\section{Result Analysis of Shift Tests}

3.1. Result Analysis of Full-Factorial Tests. Minitab [25] is used to conduct analysis of variance (ANOVA) of test data to find out the key factors that affect three evaluation indexes of shift quality. The results of the analysis are shown in Tables 3-5.
It can be concluded from Table 3 that the influence of oil pressure on speed drop is significant at the level of 0.005 , and the influence of engine speed on speed drop is significant at the level of 0.05 . It can be found that oil pressure is the main factor that affects the speed drop. From Tables 4 and 5, it can be concluded that the influence of engine speed on dynamic load and sliding friction is significant, while the influence of 
TABLE 1: Table of factors and levels.

\begin{tabular}{|c|c|c|c|c|c|}
\hline Numbers & Oil pressure $(\mathrm{MPa})$ & Engine speed (r/min) & Speed drop (r/min) & Dynamic load & Sliding friction $(\mathrm{KJ})$ \\
\hline Test 1 & 1 & 1040 & 83.00 & 2.13 & 3776 \\
\hline Test 2 & 2 & 1040 & 67.50 & 2.22 & 3290 \\
\hline Test 3 & 3 & 1040 & 56.50 & 2.36 & 2568 \\
\hline Test 4 & 4 & 1040 & 55.00 & 2.45 & 2313 \\
\hline Test 5 & 5 & 1040 & 51.00 & 2.67 & 2283 \\
\hline Test 6 & 1 & 1140 & 139.75 & 2.35 & 7873 \\
\hline Test 7 & 2 & 1140 & 75.25 & 2.38 & 4659 \\
\hline Test 8 & 3 & 1140 & 68.25 & 2.56 & 3768 \\
\hline Test 9 & 4 & 1140 & 56.75 & 2.74 & 3302 \\
\hline Test 10 & 5 & 1140 & 60.25 & 2.66 & 3079 \\
\hline Test 11 & 1 & 1240 & 108.00 & 3.16 & 5578 \\
\hline Test 12 & 2 & 1240 & 74.25 & 3.54 & 3719 \\
\hline Test 13 & 3 & 1240 & 67.50 & 3.68 & 3866 \\
\hline Test 14 & 4 & 1240 & 70.50 & 3.66 & 3554 \\
\hline Test 15 & 5 & 1240 & 64.00 & 3.98 & 3266 \\
\hline Test 16 & 1 & 1340 & 122.25 & 3.20 & 7269 \\
\hline Test 17 & 2 & 1340 & 97.50 & 3.52 & 5857 \\
\hline Test 18 & 3 & 1340 & 77.25 & 3.97 & 4543 \\
\hline Test 19 & 4 & 1340 & 75.75 & 4.08 & 4012 \\
\hline Test 20 & 5 & 1340 & 68.75 & 4.13 & 4246 \\
\hline Test 21 & 1 & 1440 & 157.75 & 3.12 & 9184 \\
\hline Test 22 & 2 & 1440 & 112.50 & 3.56 & 7201 \\
\hline Test 23 & 3 & 1440 & 95.50 & 3.82 & 6379 \\
\hline Test 24 & 4 & 1440 & 92.50 & 4.04 & 5207 \\
\hline Test 25 & 5 & 1440 & 76.25 & 4.12 & 4859 \\
\hline
\end{tabular}

TABLE 2: Table of switching quality test based on RSM.

\begin{tabular}{|c|c|c|c|c|c|}
\hline Numbers & Oil pressure $(\mathrm{MPa})$ & Engine speed $(\mathrm{r} / \mathrm{min})$ & Speed drop $(\mathrm{r} / \mathrm{min})$ & Dynamic load & Sliding friction (KJ) \\
\hline Test 1 & 3 & 1240 & 67.50 & 3.68 & 3866 \\
\hline Test 2 & 3 & 1240 & 67.50 & 3.68 & 3866 \\
\hline Test 3 & 4 & 1140 & 56.75 & 2.74 & 3302 \\
\hline Test 4 & 2 & 1140 & 75.25 & 2.38 & 4659 \\
\hline Test 5 & 3 & 1240 & 67.50 & 3.68 & 3866 \\
\hline Test 6 & 3 & 1440 & 95.50 & 3.82 & 6379 \\
\hline Test 7 & 3 & 1040 & 56.50 & 2.36 & 2568 \\
\hline Test 8 & 5 & 1240 & 64.00 & 3.98 & 3266 \\
\hline Test 9 & 3 & 1240 & 67.50 & 3.68 & 3866 \\
\hline Test 10 & 1 & 1240 & 108.00 & 3.16 & 5578 \\
\hline Test 11 & 4 & 1340 & 75.75 & 4.08 & 4012 \\
\hline Test 12 & 3 & 1240 & 67.50 & 3.68 & 3866 \\
\hline Test 13 & 2 & 1340 & 97.50 & 3.52 & 5857 \\
\hline
\end{tabular}

TABLE 3: ANOVA with all-factors test for speed drop.

\begin{tabular}{lccccc}
\hline Source of error & Degree of freedom & Sum of squares & Mean square value & Value of $F$ & Significance \\
\hline Oil pressure A & 4 & 10820 & 2704.97 & 27.50 & $※ ※$ \\
Engine speed B & 4 & 5310 & 1327.46 & 13.49 & $※$ \\
\hline
\end{tabular}

Note.The symbol $※$ represents significance at the level of 0.05 ; the symbol $※$ represents significance at the level of 0.005 .

TABle 4: ANOVA with all-factors test for dynamic load.

\begin{tabular}{lccccc}
\hline Source of error & Degree of freedom & Sum of squares & Mean square value & Value of $F$ & Significance \\
\hline Oil pressure A & 4 & 1.6589 & 0.41473 & 22.46 & $※$ \\
Engine speed B & 4 & 9.5818 & 2.39545 & 129.71 & $※$ \\
\hline
\end{tabular}

Note. The symbol $※$ represents significance at the level of 0.05 ; the symbol $※ ※$ represents significance at the level of 0.005 . 
TABLE 5: ANOVA with all-factor test for sliding friction.

\begin{tabular}{lccccc}
\hline Source of error & Degree of freedom & Sum of squares & Mean square value & Value of $F$ & Significance \\
\hline Oil pressure A & 4 & $3.38 E+07$ & $8.4 E+06$ & 22.33 & $※$ \\
Engine speed B & 4 & $3.28 E+07$ & $9.56 E+06$ & 25.20 & $※ ※$ \\
\hline
\end{tabular}

Note. The symbol $※$ represents significance at the level of 0.05 ; the symbol $※ ※$ represents significance at the level of 0.005 .

oil pressure is low. The engine speed is the main factor that affects the dynamic load and sliding friction.

\subsection{Result Analysis of RSM Tests}

3.2.1. Speed Drop Analysis of RSM Tests. According to the results of shift tests based on response surface methodology in Table 2, multiple regression fitting was carried out through auxiliary software Design-Export. And the binary regression equation with speed drop $y_{1}$ as the response value was obtained. The function is as shown below:

$$
\begin{aligned}
y_{1}= & -28.56 x_{1}-0.41 x_{2}-0.008 x_{1} x_{2}+4.66 x_{1}^{2} \\
& +0.0002 x_{2}^{2}+320.83 .
\end{aligned}
$$

In function (4), $x_{1}$ refers to oil pressure and $x_{2}$ refers to engine speed. Regression variance analysis and significance test were performed on the model, and the results are shown in Table 6.

The total $P$ value 1 of the model is $<0.0001$, indicating that the regression model is highly significant. The value of corrected correlation coefficient $\left(R^{2}\right.$ Adj $)$ is 0.9917 . It is proved that $99.17 \%$ of the variation of speed drop comes from engine speed and oil pressure, and the liner relationship is significant. Therefore, this model can be used to analyze and predict the speed drop.

The variation coefficients $(\mathrm{CV})$ reflect the confidence of the model; the lower the value of $\mathrm{CV}$, the higher the confidence of the model. The value of CV in this model is $1.96 \%$; it proves that the model can reflect the real value well.

When the value of $P<0.05$, it proves that the influence of this factor on the speed drop is very significant. As is shown in Table 6, liner terms A and B and quadratic terms $A^{2}$ and $\mathrm{B}^{2}$ have significant influence. It proves that the relationship between speed engine, oil pressure, and speed drop is not simple linear. $P$-value 2 of interaction between oil pressure and engine speed $(\mathrm{AB})$ is 0.3025 , and it proves that the interaction influence is not as significant as other terms. The response surface diagram and contour map of interaction between oil pressure and engine speed $(\mathrm{AB})$ in the regression model are shown in Figure 5.

It can be observed from Figure 5 that speed drop first decreases and then increases with the decreases of oil pressure and engine speed. That is, the speed drop can achieve a minimum value when the appropriate oil pressure and engine speed are taken. Through calculation, the minimum value of speed drop within domain is obtained when the oil pressure is $2.29 \mathrm{MPa}$ and the engine speed is $1222 \mathrm{r} / \mathrm{min}$.
3.2.2. Dynamic Load Analysis of RSM Tests. Multiple regression fitting was carried out through auxiliary software Design-Export. And the binary regression formula with dynamic load $y_{2}$ as the response value was obtained. The function is shown in function 5. And regression variance analysis and significance test were performed on the model, and the results are shown in Table 7 . In function $5, x_{1}$ refers to oil pressure and $x_{2}$ refers to engine speed.

$$
\begin{aligned}
y_{2}= & -0.208 x_{1}+0.041 x_{2}+0.0005 x_{1} x_{2}-0.033 x_{1}^{2} \\
& -0.0000153 x_{2}^{2}-24.609 .
\end{aligned}
$$

The total $P$-value 3 of the model is $0.0037<0.05$, indicating that the regression model is highly significant. The coefficient of adjustment is 0.8832 ; it proves that the fitting accuracy of the model is high. The value of variation coefficients $(\mathrm{CV})$ in the model is $7.75 \%$, and it is proved that the model can better reflect the real value.

When the value of $P<0.05$, it proves that the influence of this factor on the speed drop is very significant. As is shown in Table 7, liner terms A and B and quadratic terms $\mathrm{B}^{2}$ have significant influence. The influence of quadratic terms $\mathrm{A}^{2}$ of oil pressure and interaction between oil pressure and engine speed $(A B)$ on dynamic load is not very significant. The response surface diagram and contour map of interaction between $\mathrm{AB}$ in the regression model are shown in Figure 6.

It can be observed from Figure 6 that dynamic load increases with the increases of oil pressure and engine speed. The minimum value of dynamic load within domain is obtained when the oil pressure is $3.86 \mathrm{MPa}$ and the engine speed is $1294 \mathrm{r} / \mathrm{min}$.

3.2.3. Sliding Friction Analysis of RSM Tests. Multiple regression fitting was carried out through auxiliary software Design-Export. And the binary regression formula with sliding friction $y_{3}$ as the response value was obtained. The function is as follows:

$$
\begin{aligned}
y_{3}= & -4.466 x_{1}-27.349 x_{2}-1.22 x_{1} x_{2}+144.183 x_{1}^{2} \\
& +0.0157 x_{2}^{2}+16966.28
\end{aligned}
$$

In the function (6), $x_{1}$ refers to oil pressure and $x_{2}$ refers to engine speed. And regression variance analysis and significance test were performed on the model, and the results are shown in Table 8.

The total $P$-value 4 of the model is $0.0006<0.05$, indicating that the regression model is highly significant. The value of corrected correlation coefficient $\left(R^{2}\right.$ Adj $)$ is 0.8838 , 
TABLE 6: Coefficient of regression equation and significance test for speed drop.

\begin{tabular}{|c|c|c|c|c|c|c|}
\hline Source of variation & Sum of squares $R^{2}$ & Degree of freedom & Mean square value & Value of $F$ & Prob $>F$ & Significance \\
\hline Model & 3073.53 & 5 & 614.71 & 288.35 & $<0.0001$ & $※ ※$ \\
\hline A & 1370.67 & 1 & 1370.67 & 642.97 & $<0.0001$ & $※ ※$ \\
\hline B & 1185.05 & 1 & 1185.05 & 555.90 & $<0.0001$ & $※ ※$ \\
\hline $\mathrm{AB}$ & 2.64 & 1 & 2.64 & 1.24 & 0.3025 & $※$ \\
\hline$A^{2}$ & 497.70 & 1 & 497.70 & 233.47 & $<0.0001$ & $※ ※$ \\
\hline $\mathrm{B}^{2}$ & 106.96 & 1 & 106.96 & 50.17 & 0.0002 & $※ ※$ \\
\hline Residual & 14.92 & 7 & 2.13 & & & \\
\hline Lack of fit & 14.92 & 3 & 4.97 & & & \\
\hline Pure error & 0.00 & 4 & 0.00 & & & \\
\hline Total variation & 3088.45 & 12 & & & & \\
\hline
\end{tabular}

The symbol $※$ represents significance at the level of 0.05 ; the symbol $※ ※$ represents significance at the level of 0.005 .

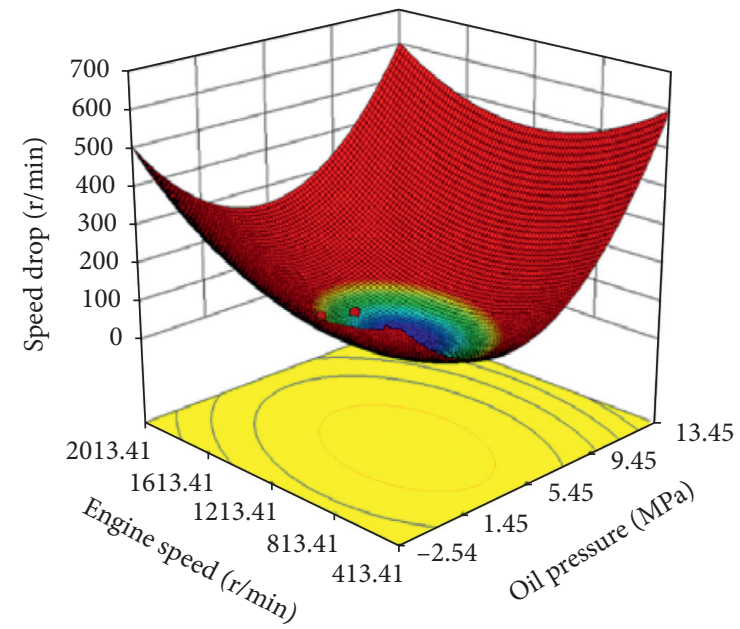

(a)

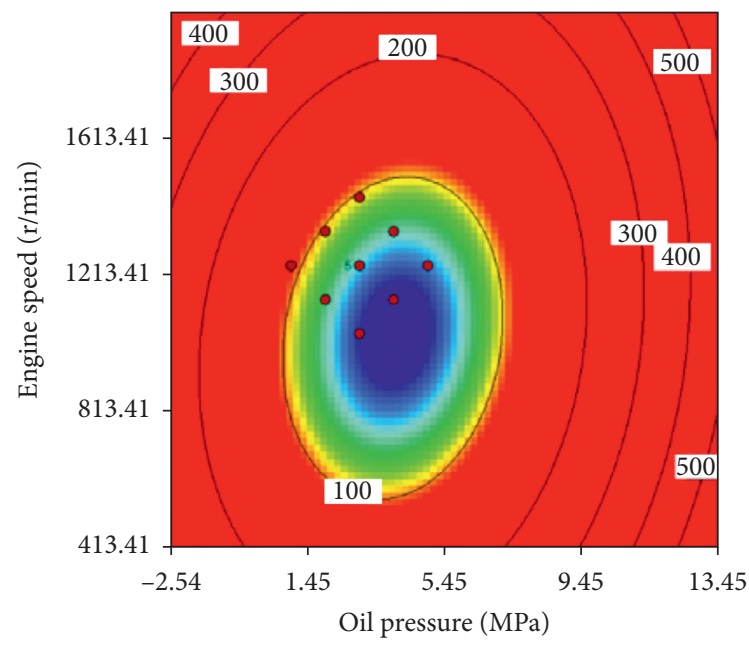

(b)

FIGURE 5: Response surface diagram and contour map of oil pressure and engine speed on interaction of speed drop.

Table 7: Coefficient of regression equation and significance test for dynamic load.

\begin{tabular}{|c|c|c|c|c|c|c|}
\hline Source of variation & Sum of squares $R^{2}$ & Degree of freedom & Mean square value & Value of $F$ & Prob $>F$ & Significance \\
\hline Model & 3.53 & 5 & 0.71 & 10.58 & 0.0037 & $※ ※$ \\
\hline A & 0.55 & 1 & 0.55 & 8.20 & 0.0242 & $※ ※$ \\
\hline $\mathrm{B}$ & 2.43 & 1 & 2.43 & 36.47 & 0.0005 & $※ ※$ \\
\hline $\mathrm{AB}$ & $1 \mathrm{E}-002$ & 1 & $1 \mathrm{E}-002$ & 0.15 & 0.7100 & $※$ \\
\hline$A^{2}$ & 0.025 & 1 & 0.025 & 0.38 & 0.5587 & $※$ \\
\hline $\mathrm{B}^{2}$ & 0.54 & 1 & 0.54 & 8.06 & 0.0251 & $※ ※$ \\
\hline Residual & 0.47 & 7 & 0.067 & & & \\
\hline Lack of fit & 0.47 & 3 & 0.16 & & & \\
\hline Pure error & 0.000 & 4 & 0.000 & & & \\
\hline Total variation & 3.99 & 12 & & & & \\
\hline
\end{tabular}

The symbol $※$ represents significance at the level of 0.05 ; the symbol $※$ represents significance at the level of 0.005 .

and the model can be used to analyze and predict sliding friction. The value of variation coefficients $(\mathrm{CV})$ in the model is $8.87 \%$, and it is proved that the model can better reflect the real value. Since the value of $A$ and $B$ both $<0.05$, therefore, the linear terms of engine speed and oil pressure have a significant influence on sliding friction. The $P$-value 5 of engine speed quadratic terms $B^{2}<0.01$, and the influence of the term is significant. The influence of quadratic terms $A^{2}$ of oil pressure and interaction between oil pressure and engine speed $(A B)$ on sliding friction is not very significant. The response surface diagram and contour map of interaction between $A B$ in the regression model are shown in Figure 7.

It can be observed from Figure 7 that the value of sliding friction first decreases and then increases with the increases of oil pressure and engine speed, and the decreasing range is greater than the increasing range. That is, the sliding friction can achieve a minimum value when the appropriate oil pressure and engine speed are taken. Through calculation, the minimum 


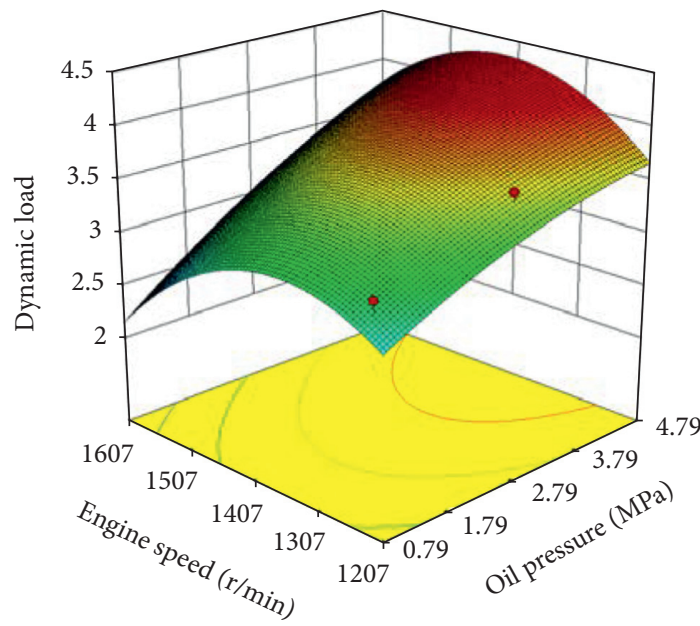

(a)

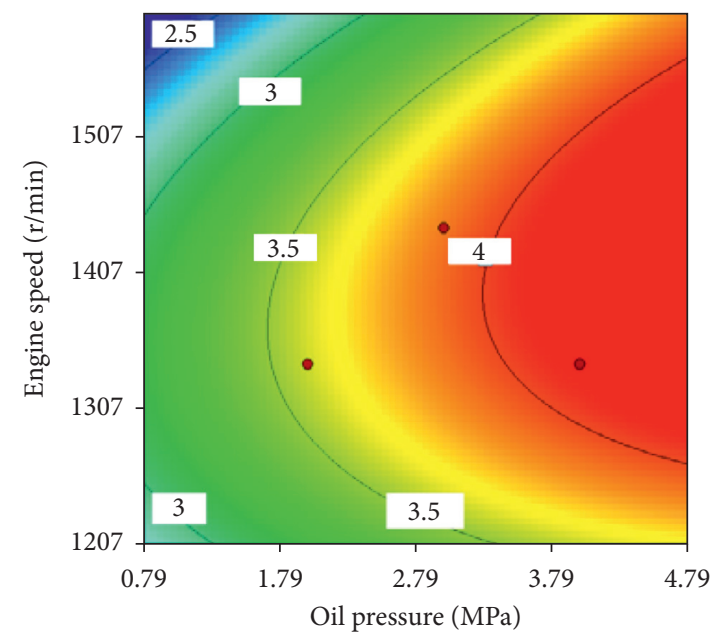

(b)

FIGURE 6: Response surface diagram and contour map of oil pressure and engine speed on interaction of dynamic load.

TABLE 8: Coefficient of regression equation and significance test for sliding friction.

\begin{tabular}{|c|c|c|c|c|c|c|}
\hline Source of variation & Sum of squares $R^{2}$ & Degree of freedom & Mean square value & Value of $F$ & Prob $>F$ & Significance \\
\hline Model & $1.354 E+007$ & 5 & $2.709 E+006$ & 19.25 & 0.0006 & $※ \circledast$ \\
\hline A & $5.104 E+006$ & 1 & $5.104 E+006$ & 36.27 & 0.0005 & $※ ※$ \\
\hline B & $7.568 E+006$ & 1 & $7.568 E+006$ & 53.79 & 0.0002 & $※ ※$ \\
\hline $\mathrm{AB}$ & 59536 & 1 & 59536 & 0.42 & 0.5361 & $※$ \\
\hline$A^{2}$ & $4.763 E+005$ & 1 & $4.763 E+005$ & 3.39 & 0.1083 & $※$ \\
\hline $\mathrm{B}^{2}$ & $5.652 E+005$ & 1 & $5.652 E+005$ & 4.02 & 0.0851 & $※ ※$ \\
\hline Residual & $9.849 E+005$ & 7 & $1.407 E+005$ & & & \\
\hline Lack of fit & $9.849 E+005$ & 3 & $3.283 E+005$ & & & \\
\hline Pure error & 0.000 & 4 & 0.000 & & & \\
\hline Total variation & $1.453 E+007$ & 12 & & & & \\
\hline
\end{tabular}

Note. The symbol $※$ represents significance at the level of 0.05 ; the symbol $※ ※$ represents significance at the level of 0.005 .

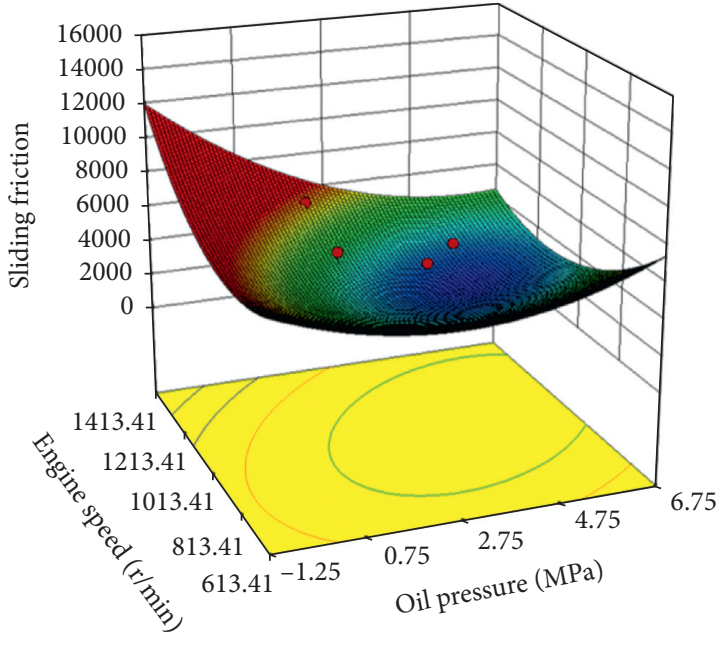

(a)

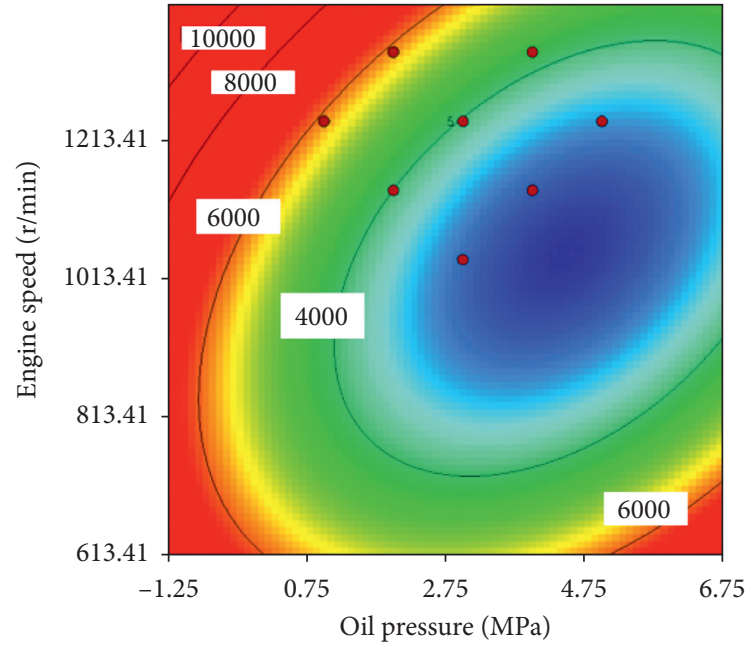

(b)

Figure 7: Response surface diagram and contour map of oil pressure and engine speed on interaction of sliding friction. 
value of sliding friction within domain is obtained when the oil pressure is $4.43 \mathrm{MPa}$ and the engine speed is $1042 \mathrm{r} / \mathrm{min}$.

\section{The Comparison of Prediction Accuracy between Four Modeling Methods}

4.1. Evaluation Model of Shift Quality Based on Stepwise Regression Analysis. In order to compare and verify the accuracy of mathematical model based on response surface methodology, the test data obtained by the RSM was used to establish mathematical model in stepwise regression analysis [26-29]. The basic theory of stepwise regression modeling is to conduct F-test for each stepwise introduced independent variable and then conduct the $t$-test with the selected variable if the variable is selected. If the test results are not significant because of the introduction of new variables, the variables that were just introduced will be removed. Stepwise regression analysis of speed drop, dynamic load, and sliding friction is conducted in Matlab Toolbox; the main program is as follows: stepwise $(X, Y,[1,2], 0.05,0.10)$. And $X$ is the combined factors in 13 groups of RSM tests, and $Y$ is the response value of each test. $[1,2]$ represents that there are two independent variables in total. The mathematical models of speed drop $y_{11}$, dynamic load $y_{22}$, and sliding friction $y_{33}$ are shown as follows, and in the functions (7), (8), and (9), $x_{1}$ refers to oil pressure and $x_{2}$ refers to engine speed.

$$
\begin{gathered}
y_{11}=-38.65 x_{1}-0.44 x_{2}+4.66 x_{1}^{2} \\
+0.000216 x_{2}^{2}+351.059 \\
y_{22}=-0.208 x_{1}+0.041 x_{2}+0.0005 x_{1} x_{2} \\
-0.033 x_{1}^{2}-0.000015 x_{2}^{2}-24.6088 \\
y_{33}=-4.47 x_{1}-27.349 x_{2}-1.22 x_{1} x_{2} \\
+144.183 x_{1}^{2}+0.0157 x_{2}^{2}+16966.3 .
\end{gathered}
$$

4.2. Accuracy of Prediction between Stepwise Modeling and RSM Modeling. In order to verify the accuracy of the two prediction mathematical models, 16 groups of test data (Table 9) are used to calculate the prediction deviation of the two mathematical models.

The predicted value 1 is the predictive value of RSM modeling, and the predictive value 2 is the predictive value of stepwise modeling. The results are shown in Table 10.

It can be concluded from Table 9 that the prediction accuracy of the mathematical model of speed drop established by stepwise regression method is $89.9 \%, 1.51 \%$ higher than that obtained by RSM. The prediction accuracy of the mathematical model of sliding friction established by stepwise regression method is $0.1 \%$ higher than RSM. The prediction accuracy of the mathematical model of dynamic load is $91.8 \%, 8.7 \%$ higher than that obtained by stepwise regression method. Therefore, the regression model established by stepwise method can be selected for the numerical prediction of speed drop and sliding friction. And the mathematical model established by RSM for the prediction of dynamic load has higher accuracy.

4.3. Comparison of the Prediction Accuracy of Four Modeling Methods. To compare more modeling methods, the general linear regression analysis is carried out on the three evaluation indexes of segment change. And the data are normalized to establish the normalized model. General linear regression analysis models are shown in formulas (10), (11), and (12), and $x_{1}$ refers to oil pressure and $x_{2}$ refers to engine speed.

$$
\begin{aligned}
& S_{1}=-16.8-10.69 x_{1}+0.09937 x_{2}, \\
& D_{1}=2.802+0.2133 x_{1}+0.0045 x_{2} \\
& H_{1}=-3664-652.2 x_{1}+7.942 x_{2} .
\end{aligned}
$$

Normalized regression models are shown in formulas (13), (14), and (15), and $x_{1}$ refers to oil pressure and $x_{2}$ refers to engine speed.

$$
\begin{gathered}
S_{2}=-1.423-0.2075 x_{1}+0.00193 x_{2}, \\
D_{2}=-3.001+0.124 x_{1}+0.002616 x_{2}, \\
H_{2}=-1.635-0.1711 x_{1}+0.002084 x_{2} .
\end{gathered}
$$

The prediction accuracy of the four modeling methods is shown in Table 11.

As can be seen from Table 11, the traditional range analysis and variance analysis can only obtain the ranking of the influence significance of the selected factors and then select a group of working points from the given working condition to make the shift quality better. The value range of this method is discontinuous and has great limitations.

Compared with the previous four modeling methods, it can be found that the RSM proposed in this paper has the highest accuracy when establishing dynamic load prediction model. Stepwise regression analysis method has the highest accuracy when establishing the prediction model of speed drop and sliding friction work.

\section{The Solutions of Optimal Shift Point}

5.1. The Establishment of the Total Shift Quality Model. In order to obtain the value of each factor when the shift quality is best, the comprehensive evaluation index related to speed drop $\eta_{1}$, dynamic load $\eta_{2}$, and sliding friction $\eta_{3}$ was established. The form is shown in

$$
y=\omega_{11} \eta_{1}+\omega_{22} \eta_{2}+\omega_{33} \eta_{3}
$$

To get the best shift quality, the minimum value of $y$ needs to be calculated. Therefore, the value of weight coefficient $\omega_{11}, \omega_{22}$, and $\omega_{33}$ needs to be determined reasonably to establish the comprehensive evaluation index. In this paper, the variance analysis and weight determination are combined, and the method of variance weight determination 
TABLE 9: Table of 16 groups of test data.

\begin{tabular}{|c|c|c|c|c|c|}
\hline Numbers & Oil pressure $(\mathrm{MPa})$ & Engine speed $(\mathrm{r} / \mathrm{min})$ & Speed drop (r/min) & Dynamic load & Sliding friction $(\mathrm{KJ})$ \\
\hline Test 1 & 1 & 1040 & 83 & 2.13 & 3776 \\
\hline Test 2 & 2 & 1040 & 67.5 & 2.22 & 3290 \\
\hline Test 3 & 4 & 1040 & 55 & 2.45 & 2313 \\
\hline Test 4 & 5 & 1040 & 51 & 2.67 & 2283 \\
\hline Test 5 & 1 & 1140 & 139.75 & 2.35 & 7873 \\
\hline Test 6 & 3 & 1140 & 68.25 & 2.56 & 3768 \\
\hline Test 7 & 5 & 1140 & 60.25 & 2.66 & 3079 \\
\hline Test 8 & 2 & 1240 & 74.25 & 3.54 & 3719 \\
\hline Test 9 & 4 & 1240 & 70.5 & 3.66 & 3554 \\
\hline Test 10 & 1 & 1340 & 122.25 & 3.2 & 7269 \\
\hline Test 11 & 3 & 1340 & 77.25 & 3.97 & 4543 \\
\hline Test 12 & 5 & 1340 & 68.75 & 4.13 & 4246 \\
\hline Test 13 & 1 & 1440 & 157.75 & 3.12 & 9184 \\
\hline Test 14 & 2 & 1440 & 112.5 & 3.56 & 7201 \\
\hline Test 15 & 4 & 1440 & 92.5 & 4.04 & 5207 \\
\hline Test 16 & 5 & 1440 & 76.25 & 4.12 & 4859 \\
\hline
\end{tabular}

TABLE 10: Comparison of predication accuracy between two models.

\begin{tabular}{|c|c|c|c|c|c|c|c|c|c|}
\hline \multirow[b]{2}{*}{$\begin{array}{l}\text { Numbers } \\
\text { of test }\end{array}$} & \multicolumn{9}{|c|}{ Parameters } \\
\hline & $\begin{array}{l}\text { Test value } \\
\text { of speed } \\
\text { drop/r/ } \\
\text { min }\end{array}$ & $\begin{array}{l}\text { Predictive } \\
\text { value } 1 / \mathrm{r} / \\
\text { min }\end{array}$ & $\begin{array}{l}\text { Predictive } \\
\text { value } 2 / \mathrm{r} / \\
\text { min }\end{array}$ & $\begin{array}{c}\text { Test value of } \\
\text { dynamic } \\
\text { load }\end{array}$ & $\begin{array}{l}\text { Predictive } \\
\text { value } 1\end{array}$ & $\begin{array}{l}\text { Predictive } \\
\text { value } 2\end{array}$ & $\begin{array}{l}\text { Test value } \\
\text { of sliding } \\
\text { friction/KJ }\end{array}$ & $\begin{array}{l}\text { Predictive } \\
\text { value } 1 / \mathrm{KJ}\end{array}$ & $\begin{array}{l}\text { Predictive } \\
\text { value } 2 / \mathrm{KJ}\end{array}$ \\
\hline 1 & 83 & 93.604 & 97.255 & 2.13 & 1.719 & 2.09 & 3776 & 2386.4 & 4375.6 \\
\hline 2 & 67.5 & 70.560 & 72.587 & 2.22 & 1.932 & 2.30 & 3290 & 3545.7 & 3534.9 \\
\hline 3 & 55 & 52.434 & 51.217 & 2.45 & 2.158 & 2.53 & 2313 & 2729.4 & 2718.5 \\
\hline 4 & 51 & 57.354 & 54.52 & 2.67 & 2.172 & 2.54 & 2283 & 2753.8 & 2742.9 \\
\hline 5 & 139.75 & 98.684 & 100.743 & 2.35 & 2.528 & 2.97 & 7873 & 4954.3 & 4941.3 \\
\hline 6 & 68.25 & 60.292 & 60.73 & 2.56 & 2.987 & 3.43 & 3768 & 3317.3 & 3304.2 \\
\hline 7 & 60.25 & 59.184 & 58.00 & 2.66 & 3.182 & 3.62 & 3079 & 2833.7 & 2820.6 \\
\hline 8 & 74.25 & 83.417 & 83.88 & 3.54 & 3.344 & 3.86 & 3719 & 4751.7 & 4736.3 \\
\hline 9 & 70.5 & 62.042 & 62.51 & 3.66 & 3.771 & 4.29 & 3554 & 3447.4 & 3432 \\
\hline 10 & 122.25 & 121.809 & 120.68 & 3.20 & 3.229 & 3.83 & 7269 & 7032.7 & 7014.7 \\
\hline 11 & 77.25 & 80.167 & 80.66 & 3.97 & 3.887 & 4.49 & 4543 & 4907.7 & 4889.7 \\
\hline 12 & 68.75 & 75.809 & 77.94 & 4.13 & 4.282 & 4.88 & 4246 & 3936.1 & 3918.1 \\
\hline 13 & 157.75 & 139.854 & 137.13 & 3.12 & 3.119 & 3.81 & 9184 & 8543.2 & 8522.5 \\
\hline 14 & 112.5 & 113.559 & 112.46 & 3.56 & 3.532 & 4.22 & 7201 & 7214.5 & 7193.7 \\
\hline 15 & 92.5 & 88.934 & 91.09 & 4.04 & 4.158 & 4.85 & 5207 & 5422.2 & 5401.4 \\
\hline 16 & 76.25 & 90.603 & 94.39 & 4.12 & 4.372 & 5.06 & 4859 & 4958.6 & 4937.8 \\
\hline $\begin{array}{l}\text { Mean } \\
\text { deviation }\end{array}$ & & 0.1161 & 0.101 & & 0.082 & 0.169 & & 0.114 & 0.113 \\
\hline $\begin{array}{l}\text { Forecast } \\
\text { precision }\end{array}$ & & $88.39 \%$ & $89.9 \%$ & & $91.8 \%$ & $83.1 \%$ & & $88.6 \%$ & $88.7 \%$ \\
\hline
\end{tabular}

TABLE 11: Comparison of predication results of different modeling methods.

\begin{tabular}{lccccc}
\hline $\begin{array}{l}\text { Prediction } \\
\text { value }\end{array}$ & $\begin{array}{c}\text { General linear } \\
\text { regression analysis }\end{array}$ & $\begin{array}{c}\text { Normalized } \\
\text { regression model }\end{array}$ & RSM & $\begin{array}{c}\text { Stepwise } \\
\text { regression } \\
\text { analysis }\end{array}$ & Range analysis and variance analysis \\
\hline $\begin{array}{l}\text { Speed drop } \\
\begin{array}{l}\text { Dynamic } \\
\text { load }\end{array}\end{array}$ & 0.847 & 0.801 & 0.883 & 0.899 & The oil pressure is the main factor affecting speed drop \\
$\begin{array}{l}\text { Sliding } \\
\text { friction }\end{array}$ & 0.893 & 0.833 & 0.918 & 0.831 & $\begin{array}{r}\text { and engine speed is the main factor affecting dynamic } \\
\text { load and sliding friction. }\end{array}$ \\
\hline
\end{tabular}




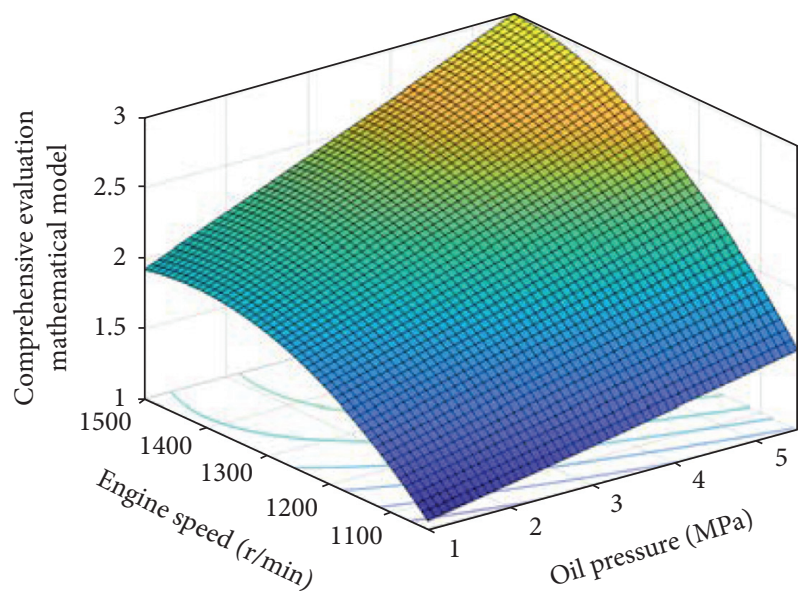

Figure 8: Response surface diagram and contour map of oil pressure and engine speed on the interaction of sliding friction.

is proposed for the establishment of multiobjective functions.

The weight is the numerical expression of the importance of the index in the overall evaluation index, and the larger the value, the greater the influence of the index on the whole. Variance is the degree to which a group of data deviates from the mean and the amount of data fluctuation. When the variance of a certain evaluation index is large, it indicates that the evaluation index fluctuates greatly and has a great influence on the overall evaluation index. Therefore, the weight of the index should be the corresponding proportional value.

There are three steps to determine the weight of the comprehensive evaluation index. Firstly, the data of speed drop $\eta_{1}$, dynamic load $\eta_{2}$, and sliding friction $\eta_{3}$ need to be normalized. Secondary, the variances of speed drop $\eta_{1}$, dynamic load $\eta_{2}$, and sliding friction $\eta_{3}$ after being normalized are obtained. Finally, the sum of the weights 1 is divided according to the variance ratio. The specific values of $\omega_{11}, \omega_{22}$, and $\omega_{33}$ are obtained and then substituted into formula (10). In the paper, the variance of the normalized speed drop is 0.0659 , the variance of the normalized dynamic load is 0.1202 , and the variance of normalized sliding friction is 0.0686. Therefore, the corresponding value of $\omega_{11}$ is $0.258, \omega_{22}$ is 0.472 , and $\omega_{33}$ is 0.27 . And the mathematical model of the comprehensive evaluation index is obtained as follows, and in function $17, x_{1}$ refers to oil pressure and $x_{2}$ refers to engine speed.

$$
\begin{aligned}
y= & -0.198 x_{1}+0.0172 x_{2}+2.89 \times 10^{-4} x_{1} x_{2} \\
& +1.34 \times 10^{-3} x_{1}^{2}-6.16 \times 10^{-6} x_{2}^{3}-10.302 .
\end{aligned}
$$

5.2. The Calculation of Optimal Shift Working Point. The comprehensive evaluation mathematical model of shift quality is drawn in Matlab and it is as shown in Figure 8. It can be seen from the figure that, with the increase of oil pressure and engine speed, the value of the comprehensive evaluation index increases gradually. Therefore, the best oil pressure at the working point is $1 \mathrm{MPa}$ and the best engine speed at the working point is $1040 \mathrm{r} / \mathrm{min}$.

\section{Conclusions}

In this paper, the HMCVT independently designed by our group is taken as the research object to study the shift process of HM1 to HM2. And the following conclusions were drawn:

(1) The paper proposed the RSM to design bench test of shift quality. Compared with the traditional test scheme, the number of tests is reduced by $48 \%$, and the test efficiency is improved. The research method proposed in this paper provides a new experimental scheme for the related research. At the same time, this method analyzes the relationship between each factor and response surface intuitively through RSM. The modeling results of RSM show that the optimal oil pressure to make the speed drop lowest is $2.29 \mathrm{MPa}$ and the engine speed is $1222 \mathrm{r} / \mathrm{min}$. The optimal oil pressure to make dynamic load lowest is $3.86 \mathrm{MPa}$ and the engine speed is $1294 \mathrm{r} / \mathrm{min}$. The optimal oil pressure to make sliding friction lowest is $4.43 \mathrm{MPa}$ and the engine speed is $1042 \mathrm{r} / \mathrm{min}$.

(2) Aiming at the defects of traditional research of shift quality, this paper proposes a mathematical model to establish the evaluation index of shift quality, and an improvement is made in the analysis method of test results. The results show that for 16 groups of test data. The maximum accuracy of the model of speed drop and sliding work established by stepwise regression method was 0.899 and 0.887 . The maximum accuracy of the dynamic load model established by RSM is 0.918 , and the obtained models can be used as prediction models to improve the research efficiency.

(3) In this paper, the variance weight method is proposed to establish the comprehensive evaluation index. This method reflects the coefficient of variation of a single evaluation index by the degree of variance fluctuation. At the same time, the method is combined with the data normalization processing to get the true variance and further determine the weight value of each evaluation index. Compared with the traditional method of subjectively determining the importance of each index, the method proposed in this paper is more objective. Through this method, the optimal oil pressure to make the shift quality best in this transmission scheme is $1 \mathrm{MPa}$ and the engine speed is $1040 \mathrm{r} / \mathrm{min}$.

\section{Data Availability}

The data used to support this paper are available from the corresponding author upon request. 


\section{Conflicts of Interest}

The authors declare that there are no conflicts of interest regarding the publication of this paper.

\section{Acknowledgments}

This research was supported by the National Key Research and Development Plan (2016YFD0701103).

\section{References}

[1] A. Rossetti and A. Macor, "Multi-objective optimization of hydro-mechanical power split transmission," Mechanism and Machine Theory, vol. 13, pp. 112-128, 2016.

[2] Y. Xia, D. Sun, D. Qin, and X. Zhou, "Optimisation of the power-cycle hydro-mechanical parameters in a continuously variable transmission designed for agricultural tractors," Biosystems Engineering, vol. 193, pp. 12-24, 2020.

[3] B. Depraetere, G. Pinte, W. Symens, and J. Swevers, "A twolevel Iterative Learning Control scheme for the engagement of wet clutches," Mechatronics, vol. 21, no. 3, pp. 501-508, 2011.

[4] S. Xiong, G. Wilfong, and J. Lumkes, "Components sizing and performance analysis of hydro-mechanical power split transmission applied to a wheel loader," Energies, vol. 12, no. 9, p. 1613, 2019.

[5] J. Wang, C. Xia, X. Fan, and J. Cai, "Research on transmission characteristics of hydromechanical continuously variable transmission of tractor," Mathematical Problems in Engineering, vol. 2020, Article ID 6978329, 14 pages, 2020.

[6] Y. Fu, Y. Liu, L. Cui, and X. Xu, "Dynamic analysis and control strategy of wet clutches during torque phase of gear shift," Journal of Mechanical Science and Technology, vol. 30, no. 4, pp. 1479-1496, 2016.

[7] J. Yu, H. Chen, and J. H. Liu, "Speed ratio follow-up control of HMCVT based on variable universe fuzzy PID," Chinese Journal of Mechanical Engineering, vol. 30, no. 10, pp. 12261232, 2019.

[8] J. B. Hu, R. Zhao, and S. H. Yuan, "A Study on improving the shift quality of hydro-mechanical transmission by electroniccontrol system," Journal of Beijing Institute of Technology, vol. 22, no. 1, pp. 36-39, 2002.

[9] C. Wei, Z. Y. Ma, X. F. Yin, J. Zhao, and X. Y. Li, "Research on the influencing factors of the range-shifting impact on HMT," Journal of Beijing Institute of Technology, vol. 35, no. 11, pp. 1122-1127, 2015.

[10] S. Manish and Z. Yi, "Shift dynamic and control of dual-clutch transmissions," Mechanism and Machine Theory, vol. 42, no. 2, pp. 168-182, 2007.

[11] Y. J. Zhang, Study on the Control Strategy of Hydro-Mechanical Continuously Variable Transmission of Tractor, Wuhan University of Technology, Wuhan, China, 2007.

[12] X. S. Zhang, Study on Shift Smoothly and Control Method of Hydro-Mechanical Continuously Variable Transmission, Jilin University, Jilin, China, 2011.

[13] X. D. Ni, S. H. Zhu, H. J. Zhang, Y. L. Chang, D. Y. OuYang, and G. M. Wang, "Experiment of shift quality factors for hydro-mechanical CVT," Transactions of Chinese Society for Agricultural Machinery, vol. 44, no. 6, pp. 29-34, Jun. 2013.

[14] X. R. Peng, The Research on Shifting Quality and Transmission Characteristics of Non-road Vehicle, Shihezi University, Xinjiang, China, 2018.

[15] G. M. Wang, S. H. Zhu, L. X. Shi, H. L. Tao, and W. S. Ruan, "Experimental optimization on shift control of hydraulic mechanical continuously variable transmission for tractor," Transactions of the Chinese Society of Agricultural Engineering, vol. 29, no. 18, pp. 51-59, 2013.

[16] Z. Zhu, X. Gao, D. Y. Pan, L. L. Cao, S. Han, and Y. Zhu, “A shifting control strategy for hydro-mechanical continuously variable transmission," Mechanical Science and Technology for Aerospace Engineering, vol. 36, no. 4, pp. 527-534, 2017.

[17] D. Qu, W. Luo, Y. Liu, B. Fu, Y. Zhou, and F. Zhang, "Simulation and experimental study on the pump efficiency improvement of continuously variable transmission," Mechanism and Machine Theory, vol. 131, pp. 137-151, 2019.

[18] F. Liu, W. Wu, J. Hu, and S. Yuan, "Design of multi-range hydro-mechanical transmission using modular method," Mechanical Systems and Signal Processing, vol. 126, pp. 1-20, 2019.

[19] A. Macor and A. Rossetti, "Optimization of hydro-mechanical power split transmissions," Mechanism and Machine Theory, vol. 46, no. 12, pp. 1901-1919, 2011.

[20] N. L. Feng, M. Q. Zhao, and B. Ma, "Performance simulation of power shift clutch during charge/discharge processes," Transactions of the Chinese Society of Agricultural Engineering, vol. 17, no. 2, pp. 68-71, 2001.

[21] B. Ma, "Dynamic performance simulation of vehicular power shift clutch charge process," Journal of Beijing Institute of Technology, vol. 20, no. 2, pp. 188-192, 2000.

[22] S. Iqbal, F. Al-Bender, A. P. Ompusunggu, B. Pluymers, and W. Desmet, "Modeling and analysis of wet friction clutch engagement dynamics," Mechanical Systems and Signal Processing, vol. 60-61, pp. 420-436, 2015.

[23] M. Durante, A. Ferramosca, L. Treppiccione et al., "Application of response surface methodology (RSM) for the optimization of supercritical $\mathrm{CO} 2$ extraction of oil from pate olive cake: yield, content of bioactive molecules and biological effects in vivo," Food Chemistry, vol. 332, 2020.

[24] Q. Hong and Y. Shi, "Multiresponse parameter optimization for the composite tape winding process based on GRA and RSM," Mathematical Problems in Engineering, vol. 2020, Article ID 2515014, 11 pages, 2020.

[25] J. Mao, H. Yin, C. Cui, and T. L. Wang, "Based on minitab confirmed most appropriate parameter of design of experiment," Journal of Coal Mine Machinery, vol. 29, no. 8, pp. 14-16, 2008.

[26] X. S. Nguyen, A. Sellier, F. Duprat, and G. Pons, "Adaptive response surface method based on a double weighted regression technique," Probabilistic Engineering Mechanics, vol. 24, no. 2, pp. 135-143, 2009.

[27] M. J. Sharma and S. J. Yu, "Stepwise regression data envelopment analysis for variable reduction," Applied Mathematics and Computation, vol. 253, pp. 126-134, 2015.

[28] Z. L. Yang, J. Chen, H. Kang, and W. Yang, "Response surface modeling method for dynamic characteristics of planetary gear reducer," Journal of Manufacturing Automation, vol. 41, no. 8, pp. 75-80, 2019.

[29] P. P. Zhang, J. P. Wang, L. S. Jiang et al., "Influence analysis and stepwise regression of coal mechanical parameters on uniaxial compressive strength based on orthogonal testing method," Energies, vol. 13, no. 14, 2020. 